\title{
A study on the hybrid mount against vibration and shock for naval ships
}

\author{
Seok-Jun Moon ${ }^{\mathrm{a}, *}$, Jeong-Seok Kwak ${ }^{\mathrm{b}}$, Jung-Hoon Chung ${ }^{\mathrm{a}}$, Yong-Jin Ji ${ }^{\mathrm{b}}$, Jeong-Sik Yoon ${ }^{\mathrm{c}}$, \\ Seung-Bok Choi ${ }^{\mathrm{d}}$, Hyun-Yup Lee ${ }^{\mathrm{e}}$, Woo-Jin Jung ${ }^{\mathrm{f}}$ and Dock-Jong Ki ${ }^{\mathrm{g}}$ \\ ${ }^{a}$ Systems Eng. Research Div., Korea Institute of Machinery and Materials, Daejeon, 305-343, Korea \\ ${ }^{\mathrm{b}}$ Super Century, Co., Yuseong, Daejeon, 305-150, Korea \\ ${ }^{\mathrm{c}}$ Future Tech, Co., Busan, 614-100, Korea \\ ${ }^{\mathrm{d}}$ Smart Structures and Systems Lab., Inha University, Incheon, 402-751, Korea \\ ' Naval Architecture \& Ocean Eng., Chungnam National University, Yuseong, Daejeon, 305-764, Korea \\ ${ }^{\mathrm{f}}$ Agency for Defense Development, Jinhae, Kyeongsangnamdo, 645-016, Korea \\ ${ }^{g}$ Dual Use Technology Center, Agency for Defense Development, Yuseong, Daejeon, 305-150, Korea
}

Received 23 March 2009

Revised 12 September 2009

\begin{abstract}
In naval ships, some methods or devices are acquired both to cut off the transmission of vibration from shipboard machineries and to protect them from external shock loading. One of the approaches is to install the passive mountings between machinery and a flexible supporting structure. More advanced performance has become necessary recently so far as at high frequencies in order to retain the stealth function of certain types of naval vessels.

For the purpose of this research, a novel hybrid mount for shipboard machinery installed on naval ships was developed. The mount is combined with a rubber mount and piezostack actuators. The rubber mount is one of the most popular and effective passive mounts to have been applied to various vibration systems to date. The piezostack actuator is featured by a fast response time, small displacement and low power consumption. Through a series of experimental tests conducted in accordance with MIL-M-17185A(SHIPS), MIL-M-17508F(SH), and MIL-S-901D which are US military specifications related to the performance requirements of the mount, it has been confirmed that the hybrid mount shows more effective performance for use in naval ships.
\end{abstract}

Keywords: Hybrid mount, rubber element, piezostack actuator, military specification

\section{Introduction}

Working machinery is one of the major sources of vibration in marine vessels. The reduction of the level of vibration transmitted to the hull structure by onboard equipment and machineries is a fundamental task both to improve crew and passenger comfort in cruise ships and to minimize the associated acoustic signature in military vessels. In naval ships, it is primarily needed to reduce a ship's vulnerability to detection by hostile sensors such as acoustic mines or passive sonar. In addition, onboard equipment and machinery must be able to withstand shock loadings which may be incurred during wartime service due to the effects of nuclear or conventional weapons. Therefore, some methods or devices are acquired both to cut off the transmission of vibration from items of shipboard machinery and to protect them from external shock loading.

One of the traditional approaches consists in installing the passive mountings between items of machinery and a flexible support structure such as rubber mounts and wire rope isolators. In particular, these passive mounting

*Corresponding author. Tel.: +82 42868 7428; Fax: +82 42868 7418; E-mail: sjmoon@kimm.re.kr. 
devices have better performance against extreme shock loads than other types of mounts. However, even if it provides adequate isolation at high frequencies, the passive solution loses its effectiveness at lower frequencies due to its own natural frequency. In the case of submarines, the advanced performance is required so far at high frequencies in order to retain the stealth function. The use of active control techniques can effectively cope with these problems. This is in part due to the employment of active mounts, which incorporated only local control strategies in many previous evaluation trials. Although such mounts can bring about a very high reduction of vibration transmission across individual mounts, unfavorable phase relationships between groups of mounts can lead to an overall performance that is less impressive. Active control devices are also very frail under shock loading. Therefore, the take up of the technology has been slow in the military marine industry. Even though some successful global control strategies have been demonstrated recently, the perception in the industry has been that the performance does not justify the investment cost [1].

Thus, it appears that the hybrid mount combined passive mounting devices with active technology represents a new alternative for naval ships. The hybrid mount generally consists of a passive part and an active part. While the passive part is responsible for supporting static loads, isolating unwanted vibration at high frequencies and shock-absorbing as a fail-safe device, the active part may reduce the resonant peak of the passive part and enhance the vibration performance at high frequencies. Several types of hybrid mounts are being studied in order to achieve favorable vibration control performance in wide frequency excitations. For example, efficient vibration isolation performance has been achieved by activating the ER fluid for large amplitude and low frequency excitations, while activating the piezo actuator for small magnitude and high frequency excitations [2]. Ichchou et al. [3] proposed a piezo-rubber mount, and experimentally demonstrated its efficacy by utilizing an adaptive control law. In Choi's work [4], both a passive rubber mount and an active piezo stack mount are adopted in order to achieve superior vibration control performance of a flexible beam structure. However, these hybrid mounts were not designed to take into account the specifications of shipboard machineries in naval ships. Annicchiarico et al. [5] presented the results of the numerical calculations used to design the active vibration control system for marine equipment, and then showed the results of a full-scale laboratory measurement campaign conducted on the test rig.

In this research, we have developed a novel hybrid mount - combined with a rubber mount and piezostack actuators - for shipboard machinery on naval ships. The rubber mount is one of the most popular and effective passive mounts to have been applied to various vibration systems. It is generally known that the rubber mount shows efficient vibration isolation performance in non-resonant frequency excitations. However, it can't effectively suppress the high-frequency vibration components induced by shipboard machinery, so the vibration performance at high frequencies can be enhanced using the active piezo stacks part.

The required design specifications of the hybrid mount are summarized in Table 1. Each mount should be able to support a static load of $100 \mathrm{~kg}$. The height of the hybrid mount should be less than 1.4 times of 7E450, which is one of US Navy's standard resilient mounts as a passive type [6]. The hybrid mount should have fundamental natural frequency of about $6 \mathrm{~Hz}$ under a $100 \mathrm{~kg}$ load. Vibration suppression performance should be enhanced by $17 \mathrm{~dB}$ or more in the range of $(100 \sim 1,000) \mathrm{Hz}$. Finally, the hybrid mount should demonstrate sufficient performance against shock loading. Through a series of experimental tests conducted in accordance with several military specifications and the vibration transmissibility concept, it is confirmed that the hybrid mount offers better performance for use in naval ships.

\section{Conceptual design}

In this research, the hybrid mount consists of passive and active elements; a rubber element as the passive one, and a piezostack element as the active one. Since the two elements have different dynamic characteristics, greater importance is attached to the conceptual design above all in order to meet the require design specifications summarized in Table 1. In addition, the mount should have incorporated into its design certain "captive features" to prevent the mounted equipment or load from coming free in the event of a failure of the rubber element due to a high impact shock or simply under normal service conditions according to MIL-M-17185A(SHIPS) [7].

When a number of mounts are used in a system, they are usually combined either in parallel or in series, or in some combination thereof [8]. Most commonly, the mounts are arranged in parallel. Figure 1 schematically depicts two mounts as springs in parallel. Here the static spring constant $k$ for the system is given by 
Table 1

Design specification of the hybrid mount

\begin{tabular}{clll}
\hline No. & Item & Property & Remarks \\
\hline 1 & Max. loading & $100 \mathrm{~kg}$ & $\pm 10 \%$ tolerance \\
2 & Natural frequency & $6 \mathrm{~Hz}$ at max. loading & $5 \mathrm{~Hz} \sim 7 \mathrm{~Hz}$ \\
3 & Height & Less than 1.4 times of 7E450 & \\
4 & Control performance & More than 17 dB of 7E450 & $100 \mathrm{~Hz} \sim 1,000 \mathrm{~Hz}$ \\
5 & Shock performance & Fail-safe & Based on MIL-S-901D \\
\hline
\end{tabular}

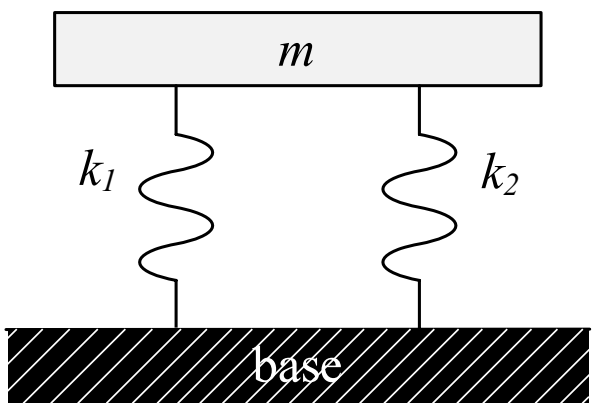

Fig. 1. Schematic diagram of two springs in parallel.

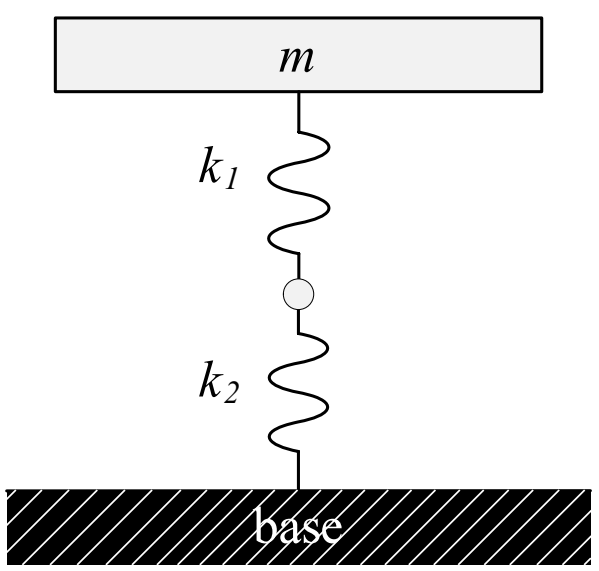

Fig. 2. Schematic diagram of two springs in series.

$$
k=k_{1}+k_{2}
$$

where $k_{1}=$ spring constant of mount 1

$k_{2}=$ spring constant of mount 2

If $k_{1}>>k_{2}$, then $k \cong k_{1}$ according to Eq. (1). When two mounts are combined in series as shown in Fig. 2, the system spring constant is given by

$$
k=\frac{1}{1 / k_{1}+1 / k_{2}}=\frac{k_{1} k_{2}}{k_{1}+k_{2}}
$$

If $k_{1}>k_{2}$, then $k \cong k_{2}$ according to Eq. (2).

While the rubber element is responsible for supporting static loading, the hybrid mount has to meet design conditions No. 1 and No. 2 as shown Table 1. In general, the natural frequency of the rubber element is much lower than that of the piezo stack element; therefore, there is no option but for the hybrid mount to connect the two elements - rubber and piezo stack - in series according to Eqs (1) and (2). However, design condition No. 3 also has to be considered carefully, since the height of the serial-connected hybrid mount exceeds that of the single mount. 


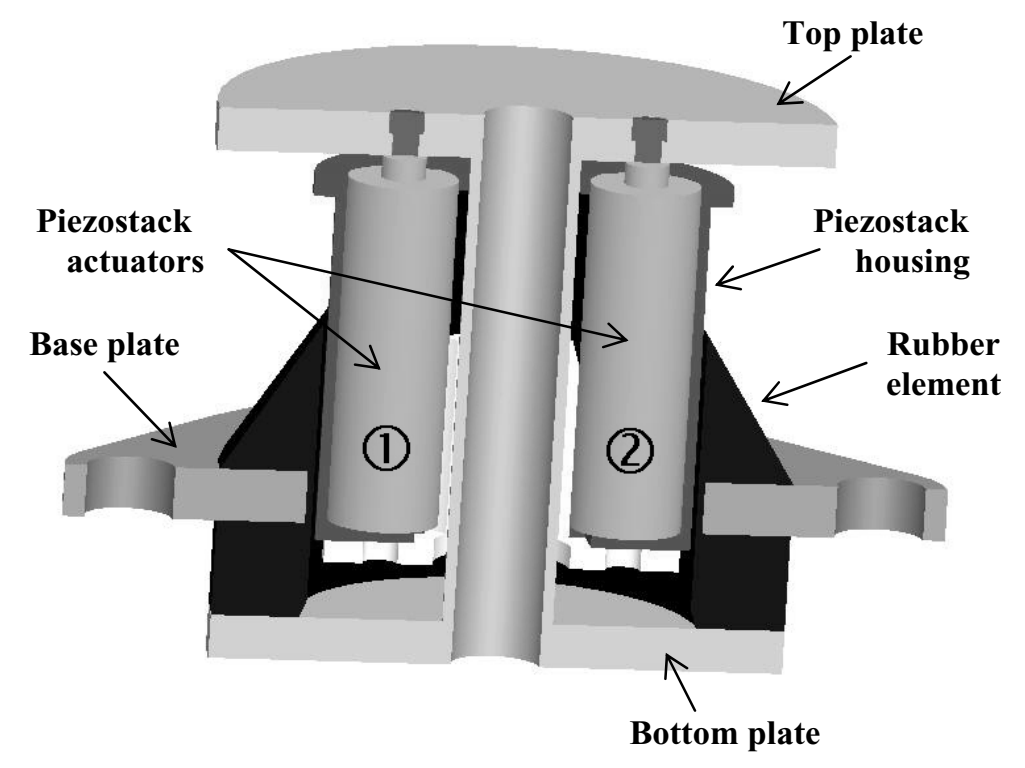

Fig. 3. Configuration of the proposed hybrid mount.

Through a series of in-depth studies of several types for the novel hybrid mount, a configuration based on the 7E450 mount was decided upon, as shown in Fig. 3. The 7E450 mount is one of the US Navy Standard mounts. Its natural frequency is $7 \mathrm{~Hz}$ with load of about $204 \mathrm{~kg}(=450 \mathrm{lb})$. The proposed hybrid mount is serially connected with the two elements, rubber and piezo stack, and two piezo stacks are inserted into the rubber element in order to meet design conditions No. 3 and No. 4. Because the piezostack actuators are enclosed within the rubber, the hybrid mount is expected to satisfy design condition No. 5. The base plate is fixed to the vibrating base. An equipment mass is loaded on the top plate which is fixed to the bottom plate by inserting a screw through the hole inside the rubber element. Since the highly stiff piezo stack is serially connected with rubber of relatively low stiffness, the stiffness of the piezostack actuators does not affect the total stiffness of the hybrid mount to any significant extent. The height of the hybrid mount is about 1.37 times that of the $7 \mathrm{E} 450$ mount.

\section{Fabrication of the hybrid mount}

The research team, including KIMM (Korea Institute of Machinery \& Materials) and its cooperating companies, has already developed key manufacturing technologies related to the US Navy's standard resilient mounts through other researches projects. The fabrication procedure for the hybrid mount was as follows:

- A mold was made for the rubber element of the hybrid mount;

- Steel components such as the base plate, top plate, center plate, and housing for the piezo stacks were made;

- The rubber element was made using the mold and center plate;

- The rubber element was reshaped to meet design conditions No. 1 and No. 2;

- The piezostack actuators were purchased from Piezomechaniks GmbH [9];

- The rubber part, steel part, piezo stacks, and so on were installed on the hybrid mount;

- Performance tests were conducted against vibration and shock loadings.

The mold for the (SC)7E450 mount, renamed as the 7E450 mount made in SuperCentury, Co., was modified by making the rubber element of the hybrid mount as shown in Fig. 4. The mold consists of four parts to completely embody complex shape due to the insertion of the piezostack actuators. All of the steel parts, with the exception of the case for the piezo stacks and the rubber compound, are the same as those of the (SC)7E450 mount. The hybrid mount's original shape after molding did not satisfy design conditions No. 1 and No. 2. A finite element analysis 
Table 2

Dimensional specifications of the proposed hybrid mount

\begin{tabular}{llc}
\hline Rubber mount & Height $(\mathrm{mm})$ & 125 \\
& Diameter $(\mathrm{mm})$ & 140 \\
& Mass $(\mathrm{kg})$ & 5.9 \\
Piezostack actuator & Height $(\mathrm{mm})$ & 89 \\
& Diameter $(\mathrm{mm})$ & 25 \\
& Mass $(\mathrm{kg})$ & 1.7 \\
\hline
\end{tabular}

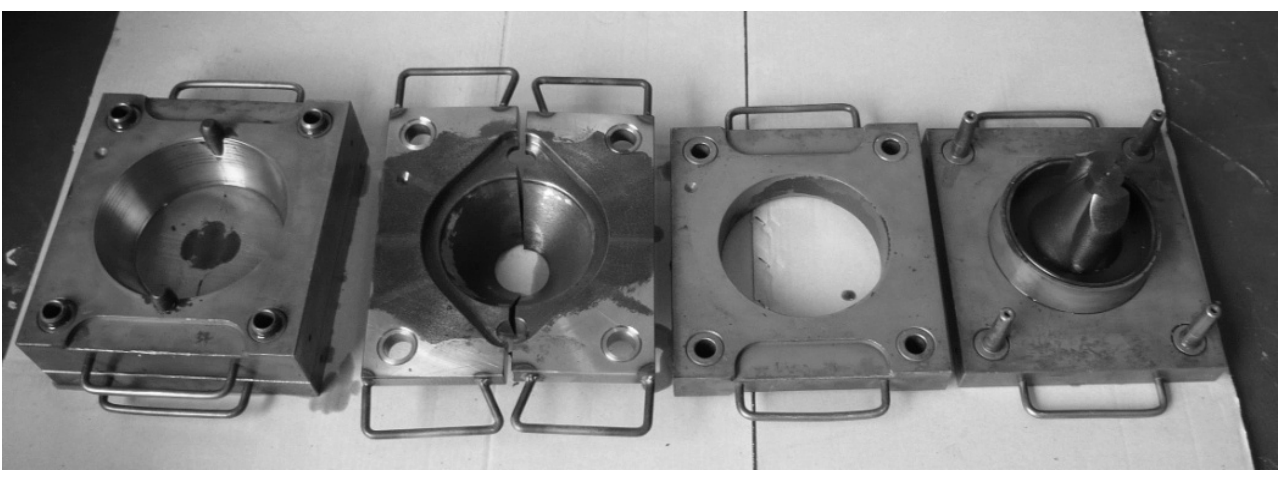

Fig. 4. Mold for the proposed hybrid mount.

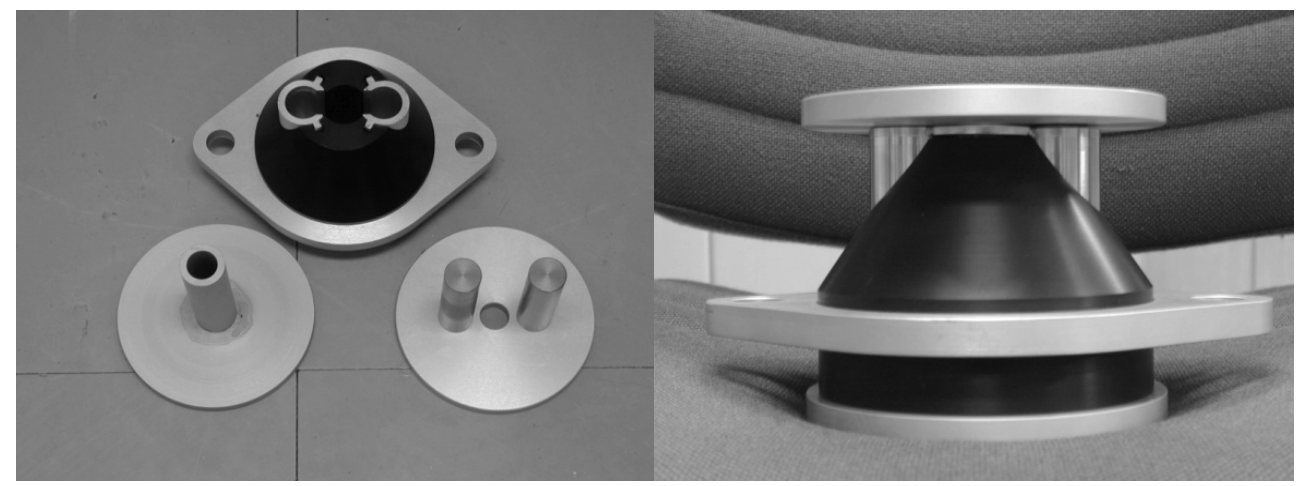

Fig. 5. Photograph of the manufactured hybrid mount.

was conducted to determine the optimum shape by using MARC, but the result was inadequate. Then, a series of experiments was carried out on several mounts of different internal shapes until the optimum shape of the rubber element was finally obtained.

In order to improve the control performance, the two piezostack actuators (Model: Piezomechanik PSt350bp/16/70/25) were selected by modeling and simulation, as described in the Modeling and Simulation section. Figure 5 shows a photograph of the manufactured and assembled hybrid mount, and Table 2 shows the dimensional specifications of the proposed hybrid mount. Certain fabricated hybrid mounts were experimentally tested to confirm the required performance, as discussed in the Performance Tests section.

\section{Modeling and simulation}

The vibration system consisting of the proposed hybrid mount and equipment can be modeled as a two degree-offreedom (2-DOF) system as shown in Fig. 6. From the model, the governing equations of motion can be derived as follows: 


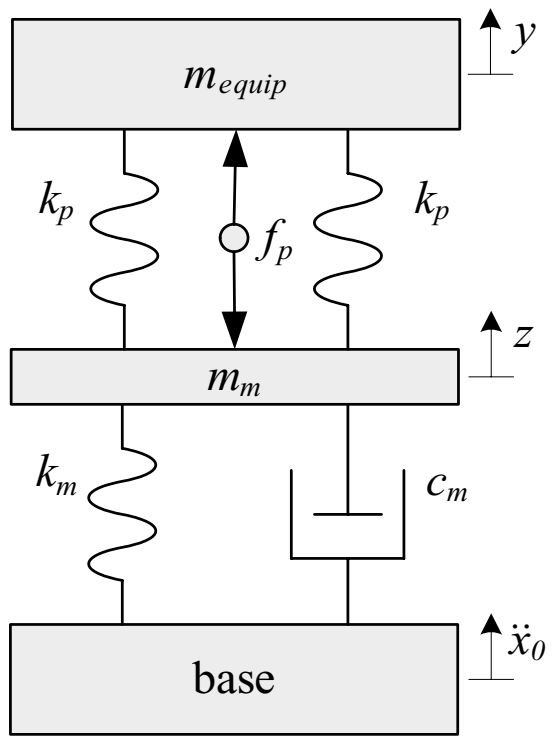

Fig. 6. 2-DOF modeling for the proposed hybrid mount.

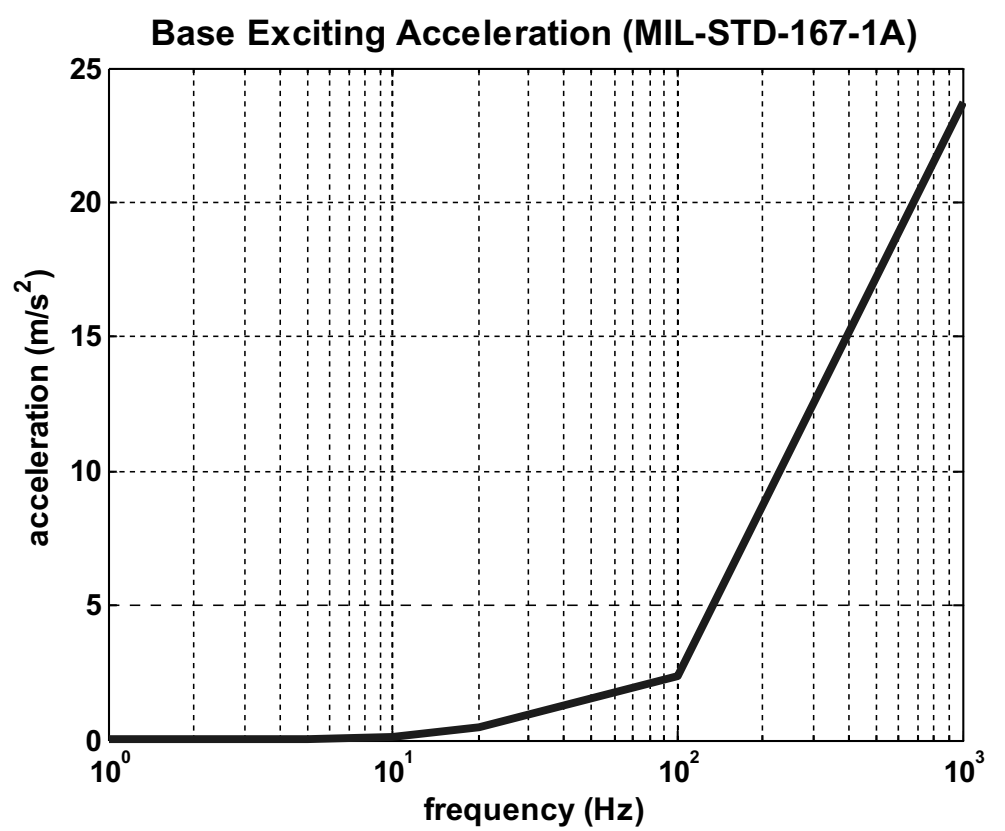

Fig. 7. Design base exciting acceleration.

$$
\begin{aligned}
& m_{m} \ddot{z}+c_{m} \dot{z}+k_{m} z+2 k_{p}(z-y)=-m_{m} \ddot{x}_{0}-f_{p} \\
& m_{\text {equip }} \ddot{y}+2 k_{p}(y-z)=-m_{\text {equip }} \ddot{x}_{0}+f_{p}
\end{aligned}
$$

where $z(t)$ and $y(t)$ are the relative displacement of the intermediate mass $\left(=m_{m}\right)$ and of the equipment $\left(=m_{\text {equip }}\right)$, respectively; $\ddot{x}_{0}(t)$ is the acceleration of the base (excitation); $k_{m}$ and $c_{m}$ are the stiffness and damping coefficients of the rubber element, respectively; $k_{p}$ is the stiffness of the piezostack actuator; and $f_{p}(t)$ is the force exerted by the piezostack actuators. As shown in Fig. 3, there is a piezostack housing between piezostack actuators and rubber element. Since the housing is connected with the piezostack actuators, it can be modeled as the intermediate mass. 


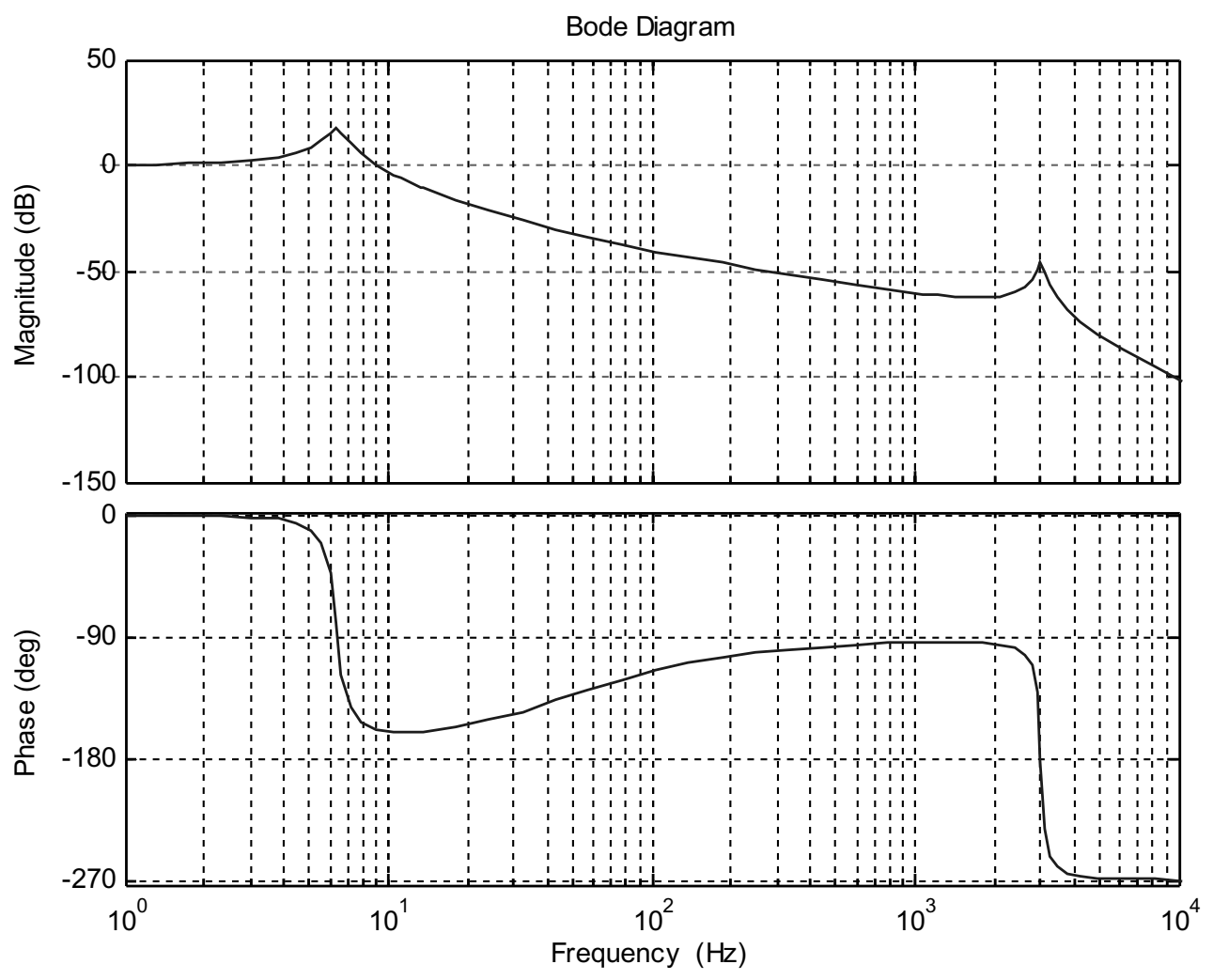

Fig. 8. Bode plot for base exciting acceleration to equipment acceleration.

The acceleration of the base, $\ddot{x}_{0}(t)$, is supposed to be excited in accordance with the military specifications for navy shipboard equipment [10], as shown in Fig. 7. To model the proposed hybrid mount, the dynamic characteristics of the piezostack actuators and the rubber element were experimentally evaluated. First, the rubber element was tested and indentified based on the 1-DOF theory. The stiffness of the rubber element was determined from resonant frequency under a load. The damping ratio of the rubber element was obtained by using the half-power bandwidth method. Next, the dynamic characteristics of the piezostack actuators were obtained by measuring the actuating force and displacement at different magnitudes of input voltage; and the maximum block forces of the two piezostack actuators were also checked. The experimental results show that the two piezostack actuators have nearly the same characteristics. Nguyen et al. [11] addressed the detail parameter identification. Figures 8 and 9 show the bode plots from base exciting acceleration to equipment acceleration and from piezo stack actuating control force to equipment acceleration, respectively. It is seen that there are two resonant peaks from rubber and piezo stack, but they are not within the interested frequency range from $100 \mathrm{~Hz}$ to $1,000 \mathrm{~Hz}$.

\section{Performance tests}

MIL-M-17185A(SHIPS) covers the general design and performance requirements as well as the specific tests for determining the suitability and performance characteristics of a resilient mount for use on naval vessels. The MILM-17508F(SH) covers the U.S. Naval Ship Research and Development Center's types of rubber elements together with tests for evaluating the rubber compounds and the completely assembled mounts. However, it is known that there are not any specific military specifications for the hybrid mounts for use on naval vessels. As a tough measure, both MIL-M-17185A(SHIPS) and MIL-M-17508F(SH) were optionally applied to the performance evaluation for the developed hybrid mount since the hybrid mount was developed based on the resilient 7E450 mount. In the case of active control performance, the vibration transmissibility concept was introduced. 
Table 3

Resonant frequencies of ten hybrid mounts

\begin{tabular}{ccccccccccc}
\hline Load $(\mathrm{kg})$ & \multicolumn{10}{c}{ Resonant frequency $(\mathrm{Hz})$} \\
\cline { 2 - 12 } & $\# 1$ & $\# 2$ & $\# 3$ & $\# 4$ & $\# 5$ & $\# 6$ & $\# 7$ & $\# 8$ & $\# 9$ & $\# 10$ \\
\hline 100 & 6.31 & 6.25 & 6.31 & 6.31 & 6.31 & 6.25 & 6.31 & 6.31 & 6.31 & 6.38 \\
\hline
\end{tabular}

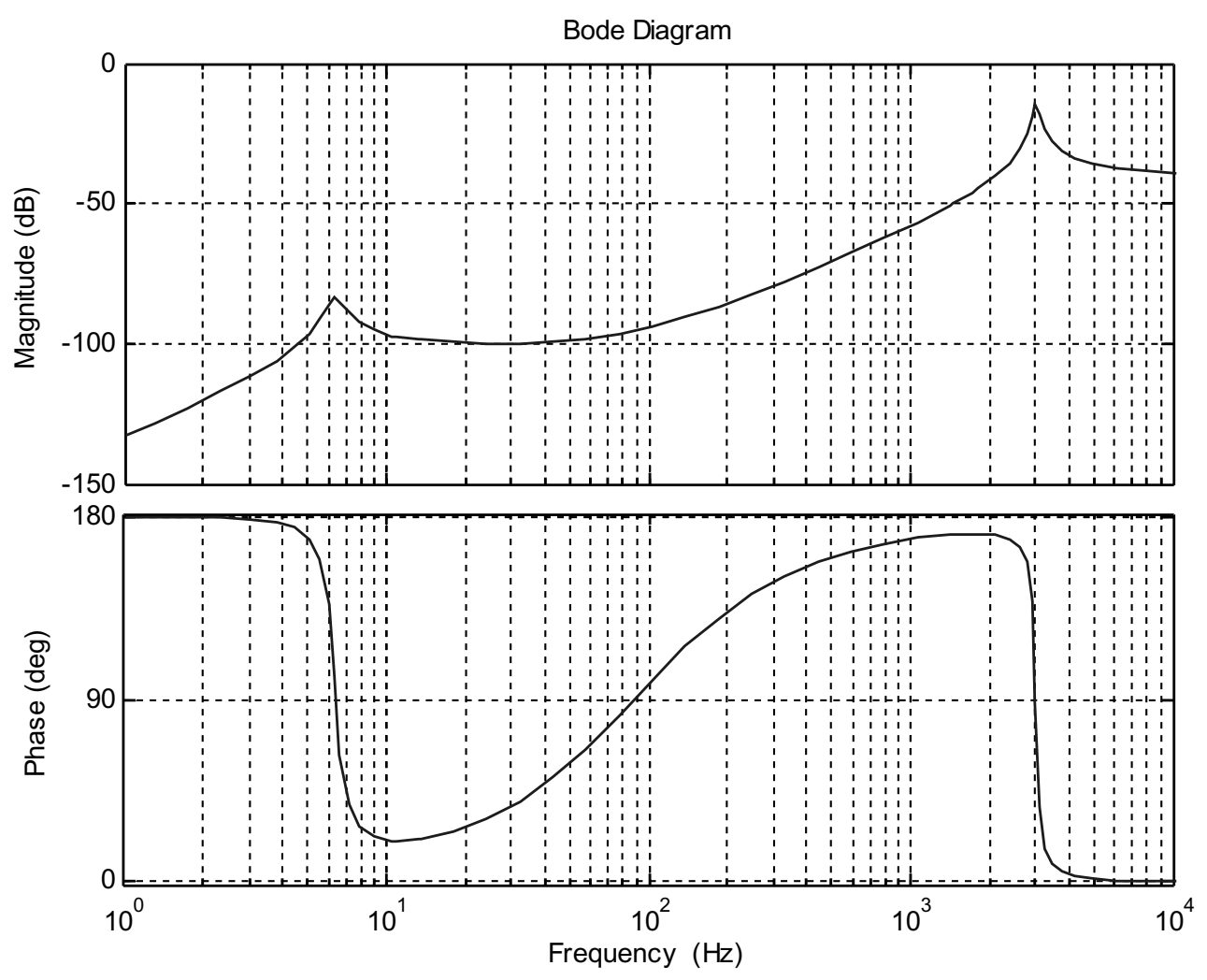

Fig. 9. Bode plot for piezostack actuating control force to equipment acceleration.

\subsection{Resonant frequency}

The resonant frequency of the mounts, tested in the axial direction, has to meet design condition No. 2 as shown in Table 1. Figure 10 shows an apparatus used to measure the resonant frequency of a mount directly. A test load was applied to the mount by weights suspended from a steel rod. The system was excited with a hydraulic shaker and some accelerometers attached to the shaking table and the top of the mount using swept sinusoidal vibration with a sweep rate low enough to achieve quasi-steady-state response. The test was conducted on 10 hybrid mounts, the results of which are summarized in Table 3.

\subsection{Deflection at rated load}

MIL-M-17508F(SH) states that the deflections of the hybrid mount, when tested in the axial direction at their respective rated loads, should be within the specified limits of Table 4 and should not show any break of separation between component parts. This test was conducted on the eight hybrid mounts using a hydraulic universal testing machine system, as shown in Fig. 11. Each mount was subjected to a single loading cycle in the axial direction. The deflection at rated load was summarized in Table 4 with the specified limits. 
Table 4

Static deflection of eight hybrid mounts

\begin{tabular}{|c|c|c|c|c|c|c|c|c|c|c|}
\hline \multirow{2}{*}{$\begin{array}{l}\text { Load } \\
(\mathrm{kg})\end{array}$} & \multicolumn{8}{|c|}{ Deflection (mm) } & \multicolumn{2}{|c|}{ Limit (mm) } \\
\hline & $\# 1$ & $\# 2$ & $\# 3$ & \#4 & $\# 5$ & $\# 6$ & \#7 & $\# 8$ & Lower & Upper \\
\hline 100 & 9.6 & 9.9 & 9.9 & 9.8 & 9.5 & 9.8 & 9.8 & 9.8 & 6.6 & 11.2 \\
\hline
\end{tabular}

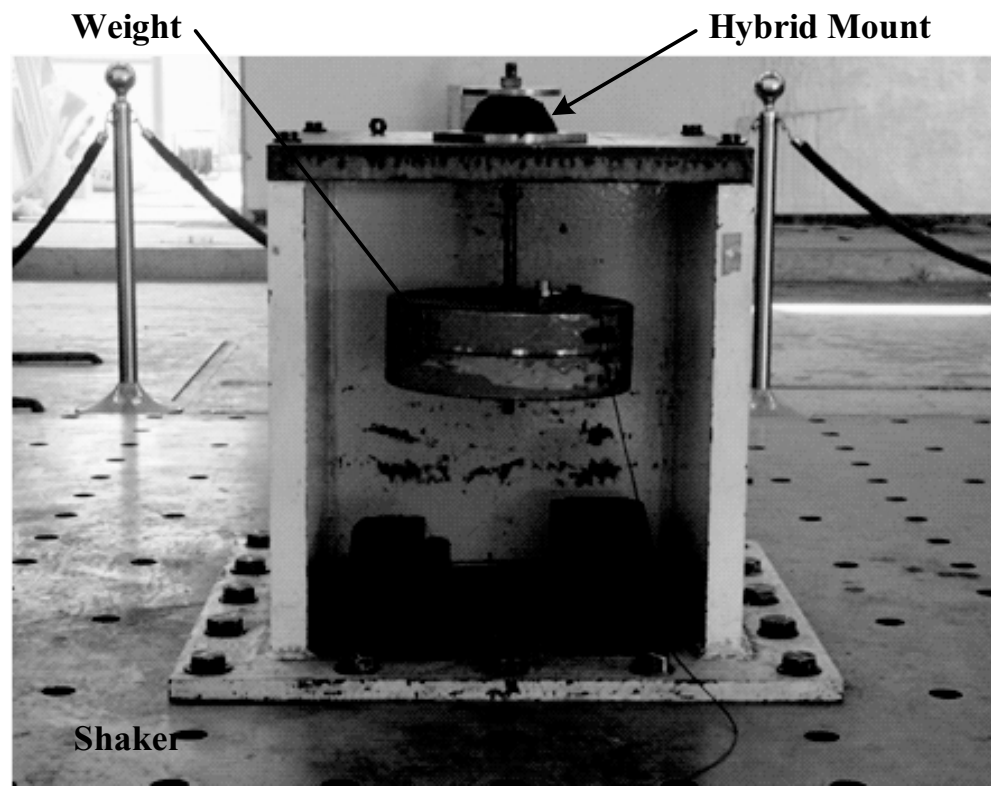

Fig. 10. Photograph of resonant frequency test for the hybrid mount.

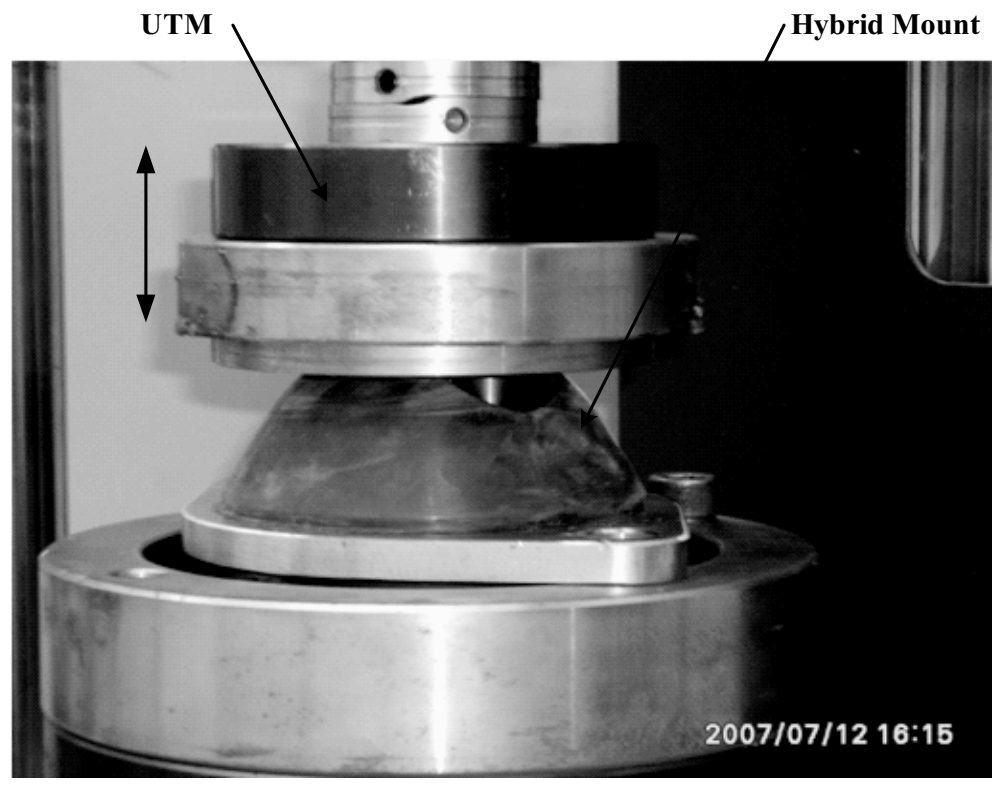

Fig. 11. Photograph of deflection test for the hybrid mount using UTM. 


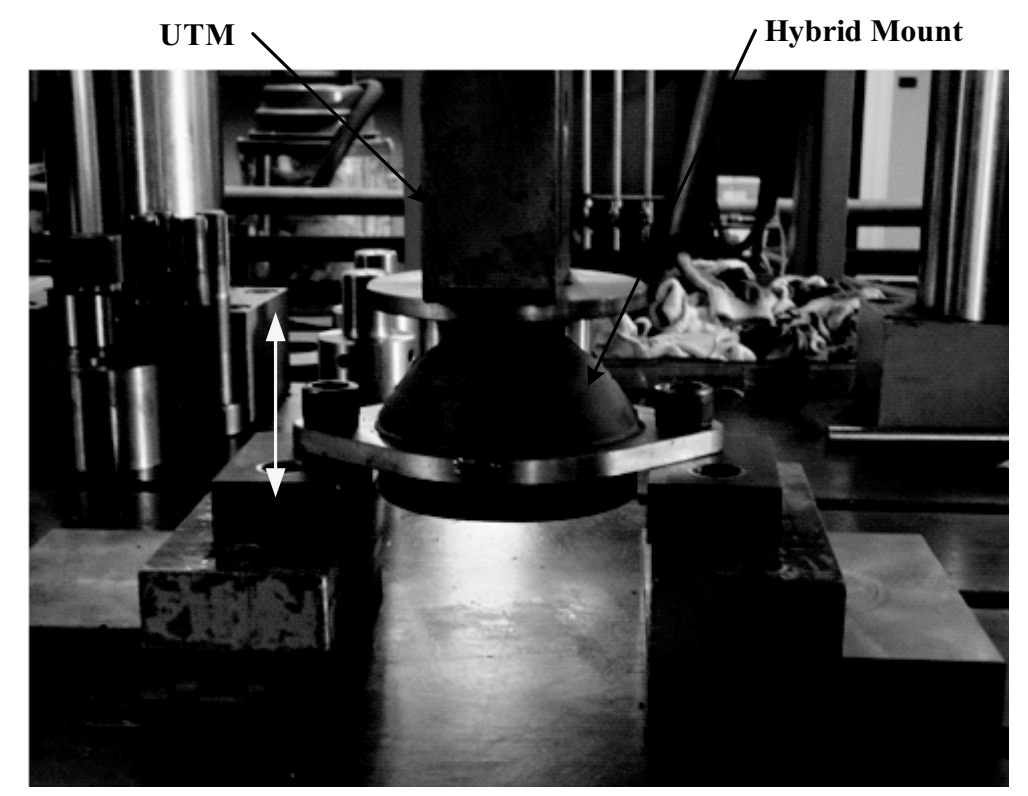

Fig. 12. Photograph of strength test in the axial direction.

\subsection{Quality of the rubber to metal bond}

MIL-M-17508F(SH) states that mounts should show no breaks, cracks, or tears in the rubber elements or evidence of delamination at rubber to metal bond interfaces. The load on the mounts, tested as specified in Section 5.2, was increased to two times the upper rated load after recording the deflection at the upper rated load. The mount held twice its upper rated load, and the appearance of the rubber element and of the rubber-to-metal bond was examined to determine conformance. No damage was reported.

\subsection{Strength test in the axial direction}

MIL-M-17508F(SH) states that mounts, when tested in the axial direction should not show any separation or break between the parts, nor any permanent deformation of the metal parts in excess of $0.794 \mathrm{~mm}(=1 / 32 \mathrm{inch})$. The mount was secured in a suitable jig and subjected to four loadings and unloadings in the axial direction, as shown in Fig. 12. The specified loads mentioned in the military specification were applied to the mount. The mount was examined during and after testing for any break or separation in the rubber or between the rubber and metal parts, as well as for deformation of the metal parts. No breaks or separations were observed.

\subsection{Strength test in the radial direction}

MIL-M-17508F(SH) states that mounts, when tested in the radial direction should not show any separation or break between the parts nor any permanent deformation of the metal parts in excess of $0.794 \mathrm{~mm}(=1 / 32 \mathrm{inch})$. Two mounts were secured by a suitable jig and tested for compressive strength in the radial direction. The mount was subjected to four loadings and unloading in the radial direction. Each mount was compressed axially to that amount at which its upper rated load rating deflected the mount during the test for deflection under the rated load in the axial direction as shown in Fig. 13. The specified loads mentioned in the military specification were applied to the mounts. No break or separations were observed. 
Table 5

Drift test results of the hybrid mount

\begin{tabular}{cccccc}
\hline \multirow{2}{*}{ Load $(\mathrm{kg})$} & \multicolumn{2}{c}{ Specified requirement } & & \multicolumn{2}{c}{ Test result } \\
\cline { 2 - 3 } \cline { 5 - 6 } & Drift $(\mathrm{mm})$ & Resonant freq. $(\mathrm{Hz})$ & & Drift $(\mathrm{mm})$ & Resonant freq. $(\mathrm{Hz})$ \\
\hline 100 & 1.27 & $5 \sim 7$ & & 0.99 & 6.44 \\
\hline
\end{tabular}

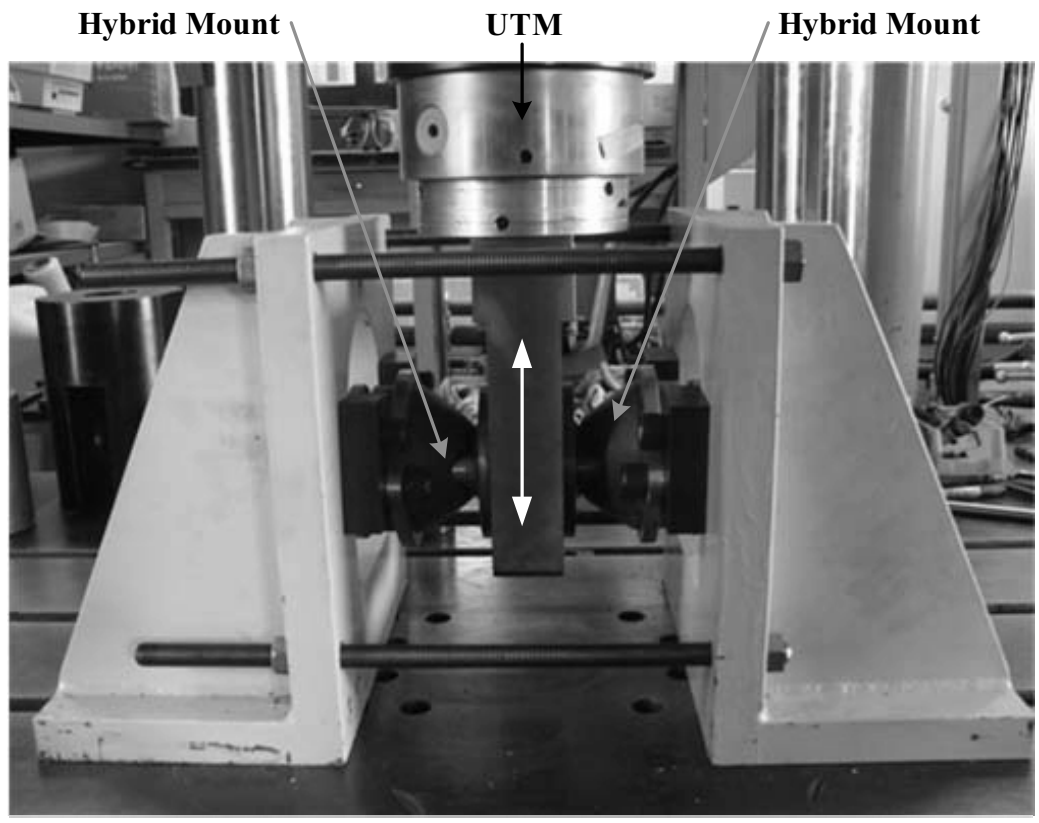

Fig. 13. Photograph of strength test in the radial direction.

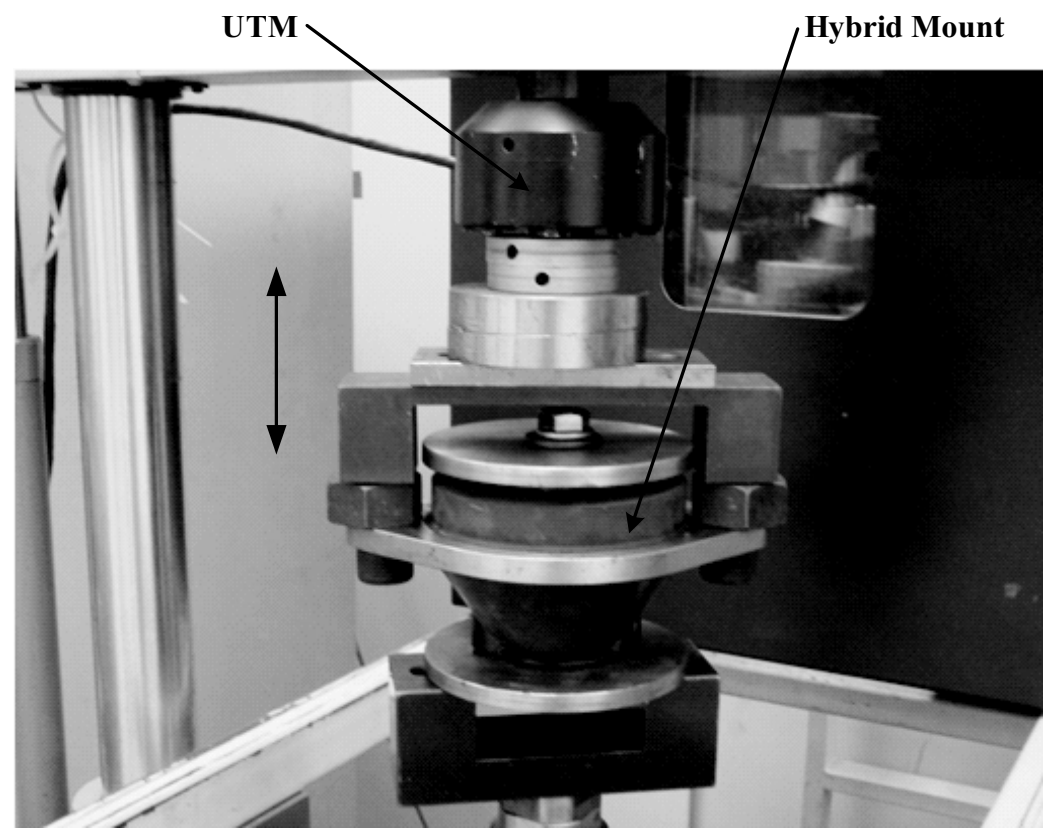

Fig. 14. Photograph of fatigue test. 
Table 6

Resonant frequencies of four hybrid mounts after shock test

\begin{tabular}{cccc}
\hline \multicolumn{4}{c}{ Resonant frequency } \\
after shock test (Hz) \\
$\# 1$ & $\# 2$ & $\# 3$ & $\# 4$ \\
\hline 6.31 & 6.19 & 6.19 & 6.31 \\
\hline
\end{tabular}

\subsection{Drift test}

Each mount was loaded to its upper rated load in the axial direction after being tested for resonant frequency. The height of the mount was measured 1 hour after loading and again after 96 hours. The difference in the two readings was taken as the drift of the mount. The mount was tested again for resonant frequency at its upper rated load. At the end of testing, the resonant frequency of the mount was observed not to have exceeded the specified requirement. Table 5 shows the specified drift requirement, resonant frequency requirement and testing results.

\subsection{Fatigue test}

Mounts should withstand fatigue loading without any sign of failure or deterioration in the rubber element, rubber to metal bond, or metal components according to MIL-M-17508F(SH). Each mount was loaded to its upper rated load in the axial direction and subjected to 500,000 cycles of vibration at its natural frequency with mount deflection of $i^{3 / 3} 1.27 \mathrm{~mm}(=0.050 \mathrm{inch})$ using a UTM, as shown in Fig. 14.

\subsection{Shock test}

MIL-M-17185(SHIPS) states that the mount should be of such design that under the hammer blows of the applicable shock test. No separation, or break in/or between components of the mount shall occur which will permit the mounted equipment to become free. The natural frequency of the mount after the shock test in the axial and radial direction should vary by no more than $\pm 15 \%$ from the average resonant frequency. The hybrid mounts were tested four at a time on the medium weight shock test machine. A dummy mass of about $400 \mathrm{~kg}$ was loaded onto the four mounts, as shown in Fig. 15. Tests were conducted in the axial and radial directions employing the testing apparatus. The intensity and number of hammer blows were applied as specified for groups II and III for medium weight equipment under specification MIL-S-901D [12]. Actually, three blows at hammer drop height $0.69 \mathrm{~m} \mathrm{(=}$ $2.25 \mathrm{ft}$ ) was applied to each group. The weight of the hammer is about $1,356 \mathrm{~kg}(=3,000 \mathrm{lb})$. No damage to the mounts and the dummy mass was observed. The test results are summarized in Table 6.

\subsection{Control performance test}

The evaluation of the active control performance for the hybrid mount was processed based on the vibration transmissibility concept, where in vibration transmissibility is expressed as follows:

$$
T_{d B}=20 \log \frac{A_{M}}{A_{B}}
$$

In Eq. (5), $T_{d B}$ is the vibration transmissibility ratio in decibels (dB); and $A_{M}$ and $A_{B}$ are the equipment acceleration and the base acceleration, respectively. In this research, a hybrid mount with controlled condition, which means the piezostack actuators are working, was compared with a (SC)7E450 passive mount. In other words, the transmissibility of the hybrid mount was compared with that of the passive mount. Figure 16 shows the experimental apparatus for the transmissibility test, which was conducted using an electromagnetic shaker. Two accelerometers were installed on the base and the equipment to measure the input and output accelerations, respectively. By exciting the system from the base with sine-sweeping vibrations, vibration transmissibility can be achieved experimentally from the measured accelerations. Under controlled condition, a robust sliding mode control method was adapted to drive the piezostack actuators. Detail description and test results on the control algorithm are presented in a reference [11]. 


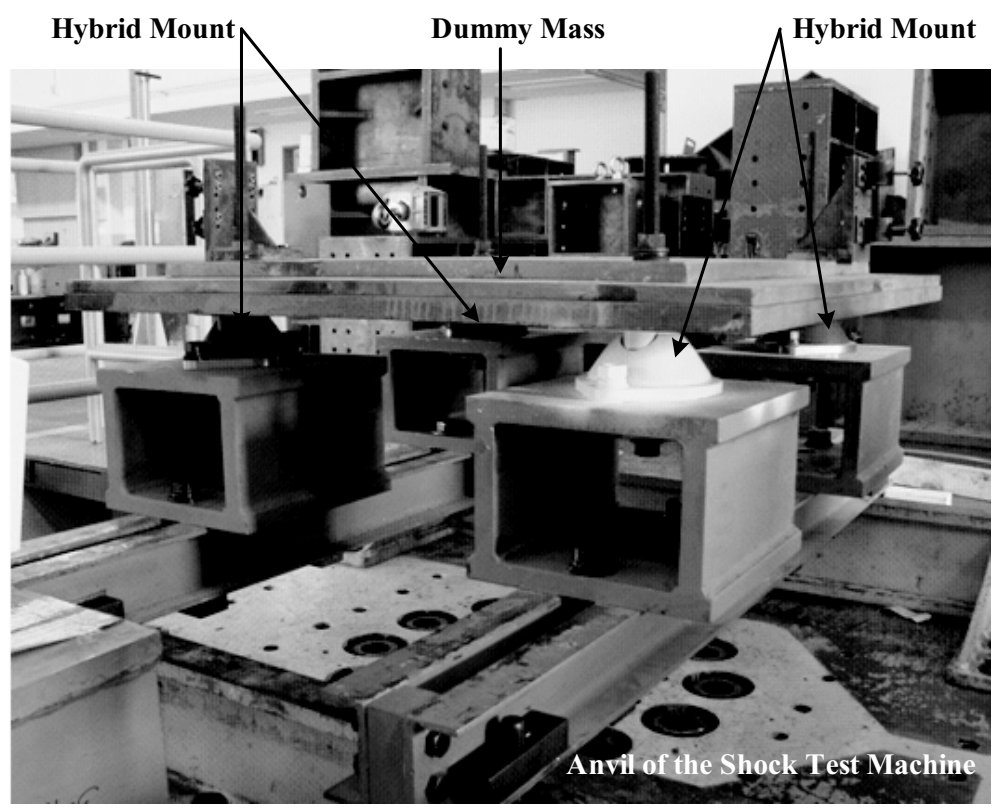

Fig. 15. Photograph of shock test.

Table 7

Control performances of the hybrid mount

\begin{tabular}{cccc}
\hline Frequency $(\mathrm{Hz})$ & $\begin{array}{c}\text { Passive mount } \\
(\mathrm{SC}) 7 \mathrm{E} 450(\mathrm{~dB})\end{array}$ & $\begin{array}{c}\text { Hybrid mount } \\
(\mathrm{dB})\end{array}$ & $\begin{array}{c}\text { Improvement } \\
(\mathrm{dB})\end{array}$ \\
\hline 100 & -30.1 & -43.8 & 13.7 \\
200 & -29.4 & -53.6 & 24.2 \\
300 & -27.9 & -74.1 & 46.2 \\
400 & -28.4 & -66.7 & 38.3 \\
500 & -27.4 & -76.6 & 49.2 \\
600 & -26.2 & -73.1 & 46.9 \\
700 & -25.5 & -74.5 & 49.0 \\
800 & -27.4 & -85.6 & 58.2 \\
900 & -27.7 & -83.5 & 55.8 \\
1000 & -28.2 & -83.8 & 55.6 \\
\hline
\end{tabular}

Several experiments with the excitation ranging from $100 \mathrm{~Hz}$ to $1,000 \mathrm{~Hz}$ were carried out to evaluate the control performance, the results of which are summarized in Table 7, where the $2^{n d}$ column is the amplitude of the transmissibility of the (SC)7E450 passive mount; the $3^{r d}$ column is the amplitude of the transmissibility of the hybrid mount with controlled, respectively. The levels of vibration transmissibility with respect to frequency were plotted in Fig. 20 for comparison. Required design specification on the performance enhancement is more than by $17 \mathrm{~dB}$ as shown in Table 1. While the hybrid mount did not satisfy the required specification at $100 \mathrm{~Hz}$, vibration suppression performance was enhanced by $17 \mathrm{~dB}$ or more in the range of $(200 \sim 1,000) \mathrm{Hz}$ compared to the (SC)7E450. As shown in Fig. 17, the hybrid mount has great control performance in the high frequency region due to dynamic characteristics of the piezostack actuator. From these results, it was assured that vibration control performance can be significantly improved by activating the piezostack actuators.

\section{Concluding remarks}

We developed a novel hybrid mount comprising a rubber mount and piezostack actuators for use with items of shipboard machinery in naval ships. The proposed hybrid mount combined a passive mounting device with active 


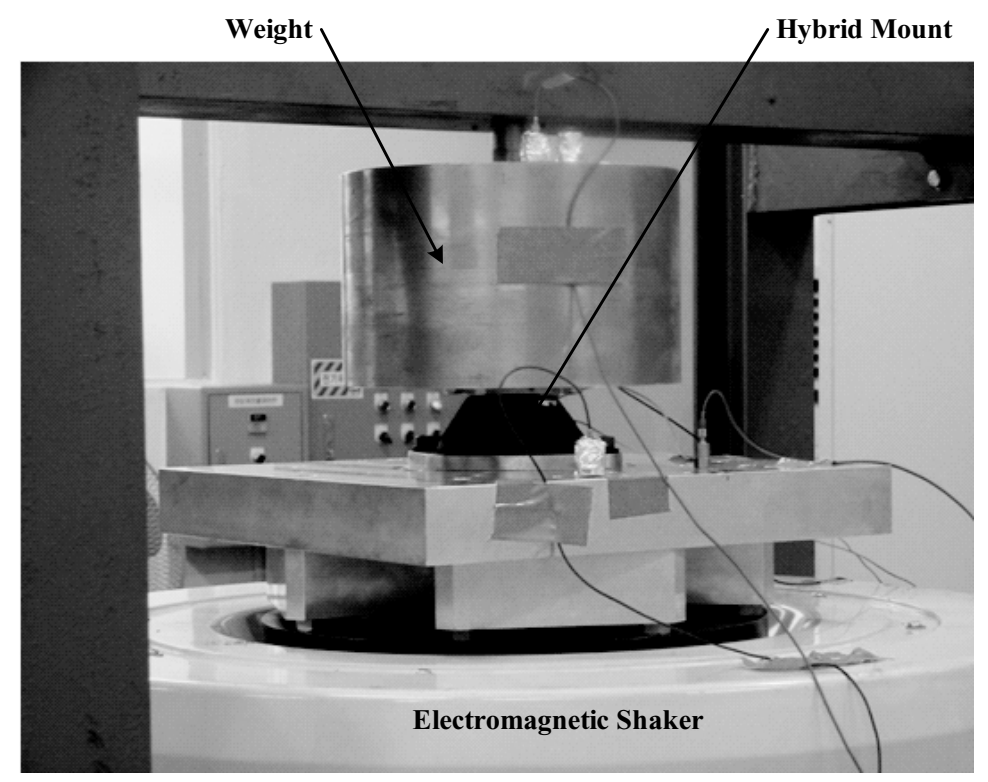

Fig. 16. Photograph of transmissibility test using electromagnetic shaker.

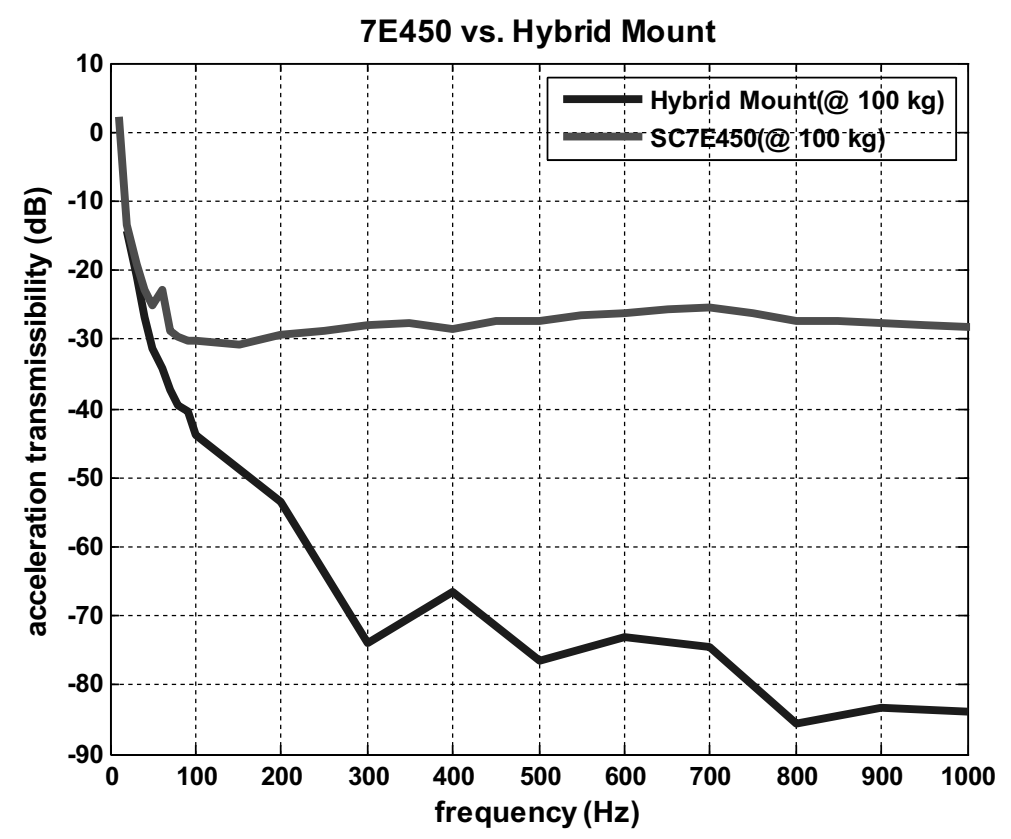

Fig. 17. Vibration transmissibility of the passive mount and hybrid mount.

technology, which represents a new alternative for naval ships. While the passive rubber element is responsible for supporting static load, isolating unwanted vibration at high frequencies and shock-absorbing as a fail-safe device, the part composed of active piezo stacks enhances vibration performance at high frequencies.

In fact, there are no specific military specifications regarding hybrid mounts for use on naval vessels. Because the hybrid mount was developed based on a resilient mount, both MIL-M-17185A(SHIPS) and MIL-M-17508F(SH) were optionally applied to the performance evaluation for the developed hybrid mount. In the case of active control performance, the concept of transmissibility was introduced. Through a series of experimental tests conducted in 
accordance with the two military specifications and MIL-S-901D, it was confirmed that the hybrid mount offered better performance than (SC)7E450, the US Navy's standard resilient mount, for use in naval ships.

As the next stage of this research, we are studying the possibility of a larger hybrid mount with a maximum loading capacity of $500 \mathrm{~kg}$, which is expected that it has a different configuration.

\section{Acknowledgment}

This work is supported by the Dual Use Technology Project (Project No. 05-DU-MC-01); the associated financial support is gratefully acknowledged.

\section{References}

[1] S. Daley, F.A. Johnson, J.B. Pearson and R. Dixod, Active vibration control for marine applications, Control Engineering Practice 12 (2004), 465-474.

[2] S.H. Kim, S.B. Choi, S.R. Hong and M.S. Han, Vibration control of a flexible structure using a hybrid mount, International Journal of Mechanical Sciences 46 (2004), 143-157.

[3] M.N. Ichchou, B. Jemai, L. Bellon and L. Jezeguel, Active rubber mount by means of piezoelectric actuators, experimental work, Smart Materials and Structures 10 (2001), 1095-1099.

[4] S.B. Choi, S.R. Hong and S.H. Kim, Beam vibration control via rubber and piezostack mounts: experimental work, Journal of Sound and Vibration 273 (2005), 1079-1086.

[5] C. Annicchiarico, E. Ferrari, Franco Bertellino, M. Pacheco and L. Stantero, Active vibrations isolation control system for marine equipments, International Conference on Marine Research and Transportation (2005), 47-55.

[6] Military Specification MIL-M-17508F(SH), Mounts, resilient: Types 6E100, 6E150, 7E450, 6E900, 6E2000, 5E3500, 6E100BB, 6E150BB, 7E450BB, and 6E900BB, Department of the Navy, Washington D.C., USA, 1990.

[7] Military Specification MIL-M-17185A(SHIPS), Mounts, resilient; general specifications and tests for (shipboard application), Department of the Navy, Washington D.C., USA, 1956.

[8] C.M. Harris and A.G. Pierson, Harris's Shock and Vibration Handbook, (5th edition), McGraw-Hill, $2002,32.1-32.41$.

[9] Piezomechaniks GmbH Website http://www.piezomechanik.com/.

[10] Military Specification MIL-STD-167-1A, Mechanical vibrations of shipboard equipment, Department of Defense, Washington D.C., USA, 2005.

[11] V.Q. Nguyen, S.M. Choi, Y.M. Han, S.B. Choi and S.J. Moon, Design of piezostack-based active mount and application to vibration control, Smart Materials and Structures 17 (2008), 1-9.

[12] Military Specification MIL-S-901D(NAVY), Shock tests, H. I. (High-Impact) shipboard machinery, equipment, and systems, requirements for, Department of the Navy, Washington D.C., USA, 1989. 

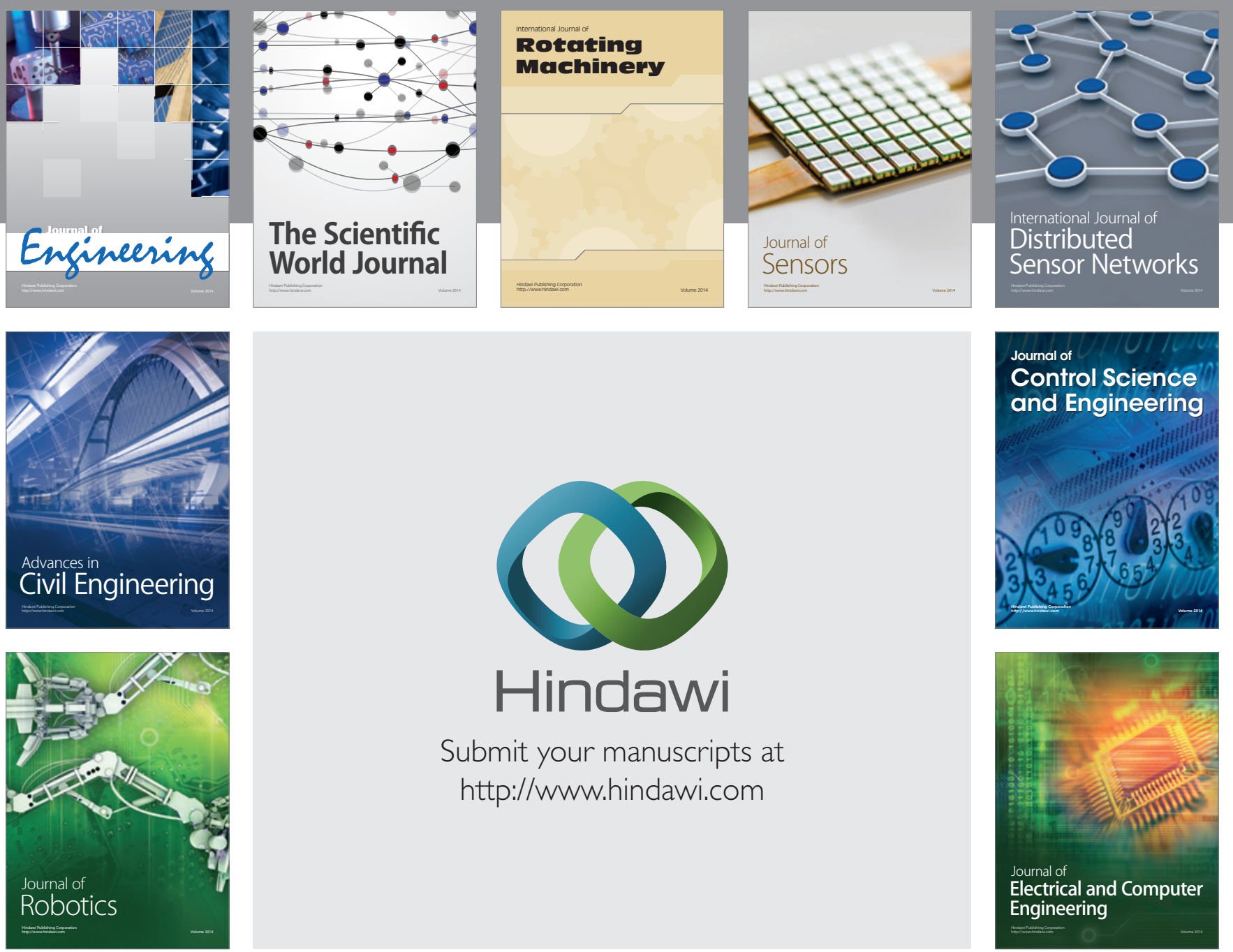

Submit your manuscripts at

http://www.hindawi.com
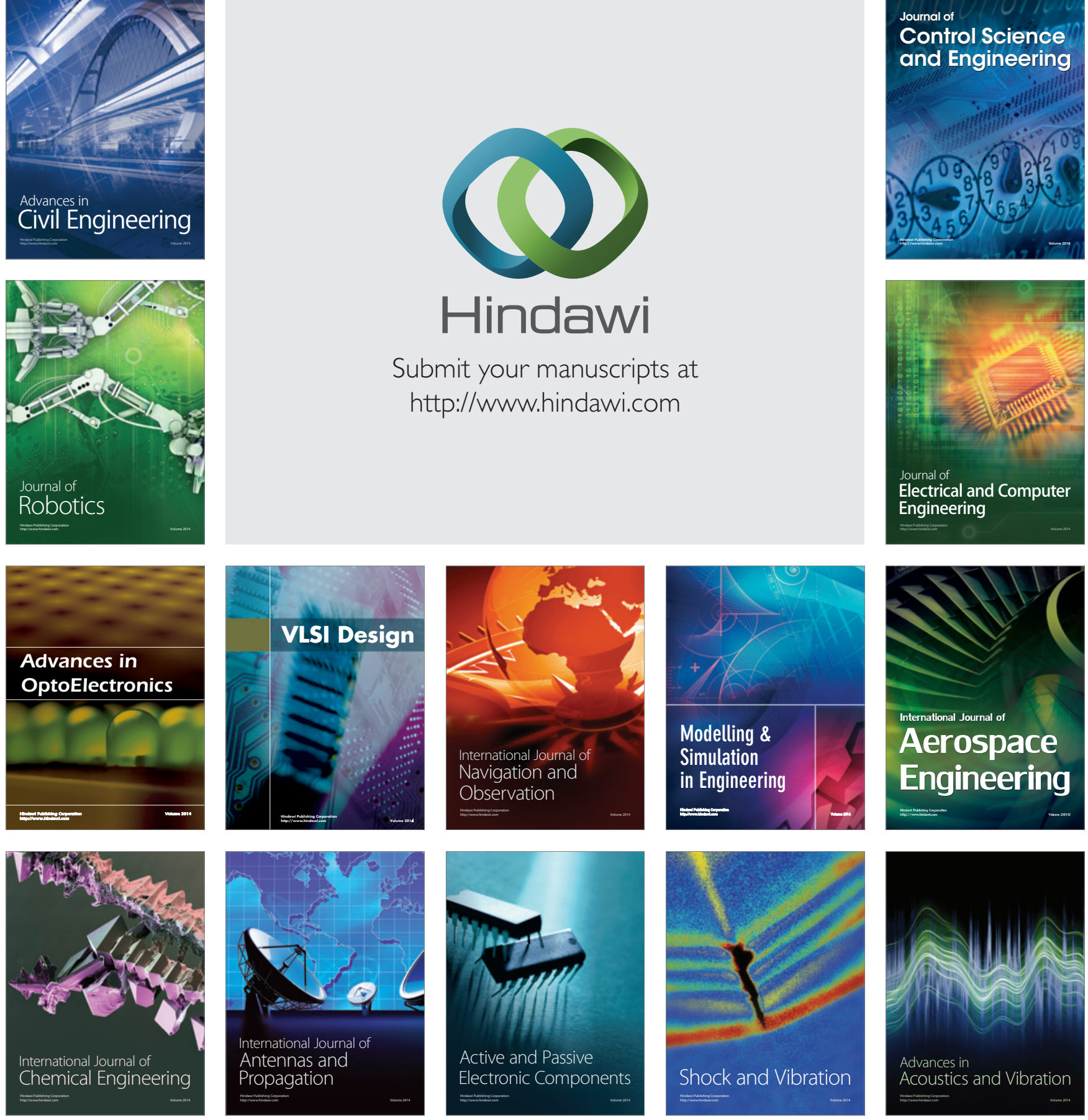